\title{
COVID-19 infection and glucocorticoids: update from the Italian Society of Endocrinology Expert Opinion on steroid replacement in adrenal insufficiency
}

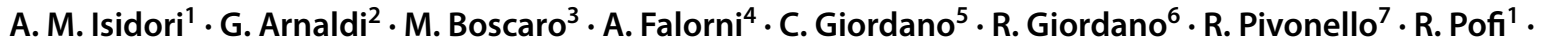 \\ V. Hasenmajer ${ }^{1}$ - M. A. Venneri ${ }^{1}$ - E. Sbardella ${ }^{1}$. C. Simeoli ${ }^{7}$. C. Scaroni ${ }^{3} \cdot$ A. Lenzi $^{1}$
}

Received: 14 April 2020 / Accepted: 17 April 2020 / Published online: 25 April 2020

(C) Italian Society of Endocrinology (SIE) 2020

Keywords Adrenal insufficiency $\cdot$ COVID-19 $\cdot$ SARS-CoV2 $\cdot$ Glucocorticoids

\author{
Abbreviations \\ SARS Severe acute respiratory syndrome \\ GC Glucocorticoid \\ CIRCI Critical illness relative corticosteroid \\ insufficiency \\ AI Adrenal insufficiency
}

In November 2019, the Italian Society of Endocrinology (SIE) has published a consensus statement on the tailoring of glucocorticoid replacement in adrenal insufficiency [1]. A few months later, a novel severe acute respiratory syndrome coronavirus (SARS-CoV2) has been recognized as

A. M. Isidori

Andrea.isidori@uniroma1.it

1 Department of Experimental Medicine, Sapienza University of Rome, Viale del Policlinico, 155, 00161 Rome, Italy

2 Clinica Di Endocrinologia E Malattie del Metabolismo, Azienda Ospedaliero-Universitaria, Università Politecnica Delle Marche, Ancona, Italy

3 UOC Endocrinologia, Dipartimento Di Medicina DIMED, Azienda Ospedaliera-Università Di Padova, Padua, Italy

4 Dipartimento Di Medicina, Università Di Perugia, Perugia, Italy

5 Section of Diabetology, Endocrinology and Metabolism, PROMISE, University of Palermo, Palermo, Italy

6 Division of Endocrinology, Department of Clinical and Biological Sciences, Diabetes and Metabolism-Department of Medical Sciences, University of Turin, Turin, Italy

7 Cattedra Unesco "Educazione Alla Salute E Allo Sviluppo Sostenibile", Dipartimento Di Medicina Clinica E Chirurgia, Sezione Di Endocrinologia, Università Federico II Di Napoli, Naples, Italy responsible for COVID-19. The outbreak has now reached pandemic level, with a high global mortality rate [2]. From February on, Italy has experienced an exponential rise in the infected which is estimated to reach 200,000 people, with an overall lethality of approximately $10 \%$ [3]. A recent Chinese series of nearly 50,000 patients with confirmed COVID-19 infection found that approximately one-out-of-five (19\%) evolve towards severe (14\%) or critical (5\%) pneumonia [4]. Several clinical trials are now testing the therapeutic options to treat lung and extra-respiratory complications of SARSCoV2 infection. While awaiting for a specific treatment strategy, the SIE task force met again to address the tailoring of corticosteroid replacement in adrenal insufficient patients coping with the stress related to COVID-19 infection.

\section{Pathophysiology of immune response in COVID-19}

Accumulating evidences have shown that COVID-19 infection follows a distinct but related stage progression. The acute respiratory distress syndrome (ARDS) observed in a significant proportion of fragile patients, roughly after the second week, is apparently non-exclusively related to uncontrolled viral replication, but rather to an out-of-control host response. The initial immune response, involving Tolllike receptors (TLRs), retinoic acid-inducible gene I (RIGI), NOD-like receptors (NLRs), and other virus sensors in respiratory epithelial cells is critical in reducing the viral load and alerting the host [5]. The response begins with the recruitment of innate immunity. If viral self-propagation is not limited, the increasing number of infected epithelial cells and cell debrides trigger a massive cytokine release-the so-called 'cytokine storm' - with hyperinflammation and immunosuppression, characterized by increased Th17 and 
CD8 cytotoxic activity and decreased memory CD4 + T helper cells [6]. The antiviral immune response represents a balancing act between the elimination of virus and immunemediated pulmonary injury. Pathology studies revealed that lung injury starts at the epithelial-interstitium-endothelial interface with increasing vascular permeability and extravasation of immune cells (mostly macrophages and granulocytes). The exudation reduces surfactant production in the alveolar space, impeding alveolar patency and gaseous diffusion [7]. Infected epithelial cells and debris bind immune cell receptors, triggering the release of inflammatory cytokines (predominantly IL-6, IL-1 and TNF alpha) and activating fibroblasts. The second phase begins when uncontrolled viral propagation induces angiotensin-converting enzyme 2 (ACE2)-directed cytotoxicity, triggering a vicious circle leading to hyperactivation of immune cells and worsening the hyperinflammation state. Patients also show lymphopenia with reduced B Cells, CD4 and CD8 T cells and $\mathrm{CD} 16^{+}$Natural Killer cells count, probably due to an increase in extravasation of dysfunctional lymphocytes and inflammation-induced apoptosis [8]. The cytokine storm leads to increased clotting, vascular inflammation, leading to disseminated thromboembolism, and hypotensive shock $[6,7]$. Although a balanced immune response seems to keep the viral infection under control, a small fraction of patients evolves through all stages [9]. In these critical cases, the priority following severe lung damage is to reduce hyperinflammation [6] and thromboembolism that are associated the increase mortality.

\section{Glucocorticoids in critical illness}

Exogenous glucocorticoids (GCs) have traditionally been associated with immune suppression. For this reason, their use has been discouraged, in the early days of the pandemic, fearing that they may favor viral propagation limiting the first line of defense, the innate immunity, that is also the most sensitive to GCs. If so, one would expect patients with chronic obstructive pulmonary disease, asthma or rheumatological disorders at an increased risk of severe COVID19 presentation. Surprisingly, these comorbidities appear under-represented in patients with severe COVID-19 [3, 10-12]. Although confounding factors and reporting bias could account for such findings, they suggest that GCs should not be blamed or discouraged. More, it cannot be excluded that GCs play a role in shaping the clinical presentation of COVID-19 [12], and a retrospective study of 200 patients with ARDS apparently showed a lower mortality among those receiving methylprednisolone [13]. The number of registered clinical trials on the use of steroids in COVID-19 pneumonia and related ARDS increases daily, aimed at investigating the effects of different formulations, associations and dosages. Due to their proved efficacy in different respiratory diseases, high lung bioavailability and strong anti-inflammatory efficacy, most on-going trials are focusing on methylprednisolone (NCT04263402, NCT04323592, NCT04343729, NCT04273321, NCT04244591), dexamethasone (NCT04327401, NCT04325061) and budesonide (NCT04331470) alone or in combination with other therapies targeting inflammation, such as Siltuximab (NCT04329650) or Tacrolimus (NCT04341038). The scope of this update, however, it to review the physiological role of cortisol that is missing in adrenal insufficient patients coping with COVID-19.

It is now recognized that GCs have both stimulating and inhibitory effects on immune response according to their timing and circulating levels [14]. In the early phases of infections, physiological GC levels are necessary to prime the immune system. This, in turn, activates hypothalamic-pituitary-adrenal (HPA) axis to increase GC release from the adrenal glands aiming to reach higher concentrations responsible for mild immunosuppression, finally reducing autoimmunity and cytokine toxicity. This ability to reduce inflammation and, ideally, fibrosis has been the rationale for the use of GCs in lung damage so far, but the associated complications and the lack of a real benefit on overall survival-with possible harm also advocated, such as gastrointestinal bleeding, hepatic failure and thromboembolism-have relegated their use to refractory shock or (by some authors) ARDS, when lung damage approaches an irreversible threshold [15]. Similarly, studies of high-dose GCs in sepsis are conflicting, with the REGARDS [16] and the more recent ADRENAL trials [200 mg hydrocortisone daily vs. placebo] showing no beneficial effects on the 90-day mortality [17], but with the APROCCHS trial showing a 28-day reduction in mortality of septic patients receiving hydrocortisone plus fludrocortisone therapy [18].

One of the reasons underpinning the conflicting evidences published so far on steroid therapy in viral respiratory infections and pneumonia could lie in the heterogeneity of the studies included in the meta-analysis assessing the mixed results of the effects of different GCs formulations (both short and long acting), given without considering the two different pathophysiological phases of the infection. In fact, if in one hand, supraphysiological dose of exogenous GCs have been shown to exerts detrimental effects in the early phase (by increasing the plasma viral load), one can argue the possibility to restrain the cytokine storm of the second, and more harmful, phase suppressing the immune overreaction by steroid treatment [19]. Moreover, in critically ill patients, the HPA axis may be unable to produce sufficient amount of corticosteroids, leading to critical illness-related corticosteroid insufficiency (CIRCI) [20]. Although the pathological features and clinical progression of COVID19 resemble those seen in other coronavirus infections for 
which various standardised steroid protocols have been proposed, recent WHO guidance on the clinical management of COVID-19 advises against corticosteroids, unless indicated for another reason [21]. Adrenal insufficiency (AI) represent such a condition, in which the rationale to a prompt correction of GC therapy is not addressed to treat lung disease, but rather is aimed to supplement the abnormal adrenal function and, thus, to save patients' life. However, specific indications have been missing, and current standards of care actually suggest increasing the GC dose if COVID-19 infection is suspected, applying the "sick-day-rule" [22].

\section{COVID-19 in adrenal insufficiency do we need to change glucocorticoid therapy?}

AI patients run an increased risk of infection due to their inefficient innate immune response, characterized by increased "classical" monocytes and decreased cytotoxic NK cells, with failure of IgG-mediated activation due to shedding of its surface receptor (CD16) [23]. The disrupted immune response could also contribute to the worsening of COVID-19 infection into severe ARDS due to impaired first-line defence. Additionally, as previously mentioned, the HPA axis plays a significant role in stress-priming the immune response and the lack of physiological increase in GC secretion in AI patients during mild illness intuitively exposes them to higher risk of progressing to more critical stages, especially if replacement therapy is not properly administered. Moreover, as noted in other critical illnesses, COVID-19 pneumonia can affect residual adrenal function [20] through cytokine release, worsening the outcome of patients with secondary AI. This is true also for tertiary adrenal insufficiency, the commonest cause for AI in the general population, resulting from long-term (more than 4 weeks) steroid treatment (equal or more than $5 \mathrm{mg}$ of prednisolone per day), especially if administered in a noncircadian fashion (e.g., night doses).

This issue is of particular importance, as the sick day rules for GC therapy during infections are still largely tailored empirically, based on a few anecdotal case reports [24] and disregarding timing and dosage [1], and most patients with tertiary adrenal insufficiency are unaware or unprepared to handle stress-doses. It must to be taken into account that mild COVID-19 symptoms such as fatigue, malaise, gastrointestinal symptoms overlap with common symptoms experienced by AI patients, even outside adrenal crisis. This makes it difficult to establish when an increase in GC therapy is actually needed, and the patients' fears may lead them to increase their dose unnecessarily.

Despite the above mentioned reports of a lower representation of subjects taking low-dose GC among those with a more severely symptomatic COVID-19 [3, 10-12], to date there is no evidence supporting a beneficial (nor a detrimental) role for corticosteroids in preventing viral infection or spread. More, considering that $60-80 \%$ of infected subjects remains completely asymptomatic [4], there is no indication to increase GC therapy in asymptomatic patients with AI.

In contrast, for the symptomatic patients, establishing the correct timing of stress dose administration relative to the degree of inflammatory damage and the desired effect on the immune system is of paramount importance in COVID-19. Thus, there is no doubt that we must to be ready to increase GC dose in AI patients. The decision on how, when, how much to do so, requires attention and cannot be left to vague indications.

\section{Management of glucocorticoid therapy in adrenal-insufficient patients with COVID-19}

Recent studies have provided further insight into GC metabolism during stress conditions. Hydrocortisone (HC) clearance significantly drops during stress challenges. In moderate stress, $100 \mathrm{mg}$ followed by $60 \mathrm{mg} / 24 \mathrm{~h}$ of $\mathrm{HC}$ infusion generally maintains cortisol levels above normal the range in most of AI patients [24]. Thus, in the early phase when patients might only develop mild COVID-19 related illness, characterized by uncomplicated upper respiratory symptoms (sore throat, nasal congestion, mild intermittent cough), with or without fatigue, malaise, anorexia, muscle ache, headache, mild nausea or diarrhoea, fever $<38^{\circ} \mathrm{C}$ and no signs of respiratory impairment, it appears safe to treat AI patients with low-to-intermediate additional doses (i.e., doubling the usual dose or adding oral $20-40 \mathrm{mg} \mathrm{HC}$ ), to replace the missing stress-induced cortisol rise (Fig. 1). At this stage of mild illness, cortisol circadian rhythm should still be mimicked. Disturbances in circadian rhythm enhance inflammatory response to exogenous pathogens [25] and, even in the absence of pathogenic challenge, they promote a shift towards a pro-inflammatory state and exhaustion of the counterregulatory mechanism necessary to drive host response [26]. In trauma patients or bacterial infections, the disruption of circadian genes rhythmicity and the change in cortisol acrophase favor the development of shock [27]. The indication is further strengthened by the observation that patients undergoing major cardiac surgery maintain some circadian rhythmicity, as the coupling between ACTH and cortisol secretion is maintained, even if blunted because of a higher basal cortisol secretion [28]. Finally, GC excess is associated with a high prevalence of psychiatric (depression, mania, anxiety) and neurocognitive disorders [29]. These can overlap with the psychological impact that the lockdown strategies have caused in many different socio-economical contexts; therefore, if not needed, it appears reasonable to 


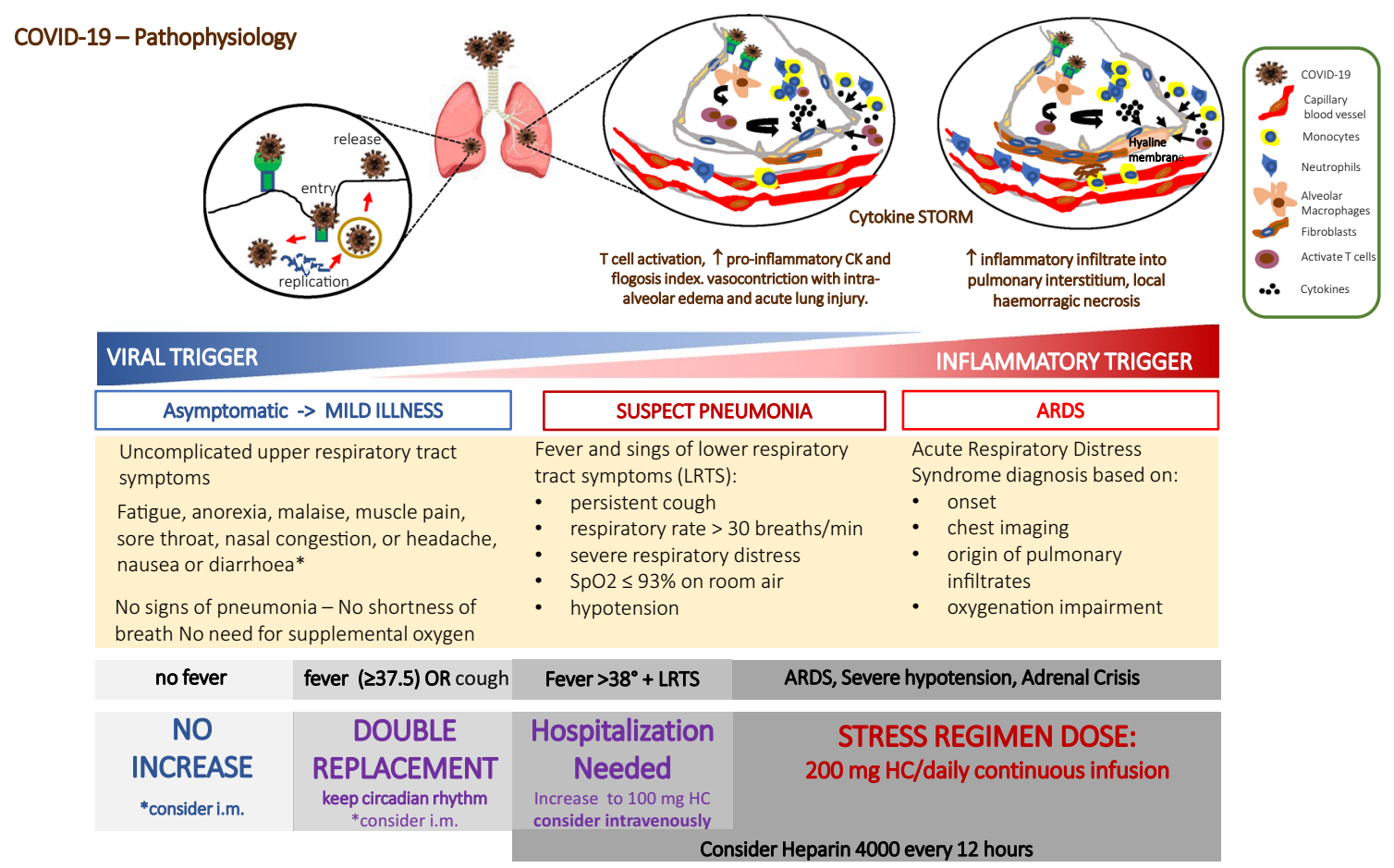

Fig. 1 Proposal for a stage-specific adjustment of glucocorticoid therapy in adrenal insufficient patients with COVID-19 infection

avoid an excessive GC load. However, in a significant proportion (20\%) of adrenal-sufficient subjects with COVID-19, the disease progresses to moderate or severe. No data are yet available in AI patients, therefore, it is mandatory that vital parameters, such as blood pressure (of utmost importance, as hypotension develops in the late phases), heart and respiratory rate and resting peripheral oxygen saturation, be monitored daily. In cases of incoming vomit (more than one day and especially within $3 \mathrm{~h}$ from the last steroid dose) and/or diarrhea, parenteral injection is mandatory. If fever increases or persists, symptoms worsen (including AI-specific signs and symptoms, such as incoming hypotension), or respiratory damage progresses with patients showing persistent cough, increased respiratory rate ( $>30$ breaths per minute) and/or $\mathrm{SpO} 2$ less than $93 \%$, (current definitions of moderate COVID-19 disease, see Fig. 1), GC therapy should be immediately increased to $100 \mathrm{mg}$ (preferentially by parenteral administration according to the clinical status) and hospitalization is needed to be ready to face an adrenal crisis and start treatment to limit immune hyperactivation (see Fig. 1). Contrary to the general population, the threshold for hospitalization should be low for worsening symptoms in AI patients, considering their risk for an adrenal crisis.

In the hospital, if clinical condition worsens and moves towards ARDS, higher dose should be started. In this context, Prete et al. recently identified an initial bolus of 50-100 $\mathrm{mg}$ of hydrocortisone followed by continuous intravenous infusion of $200 \mathrm{mg}$ (per day?) as the most appropriate regimen in AI patients with sepsis [30]. This protocol is able not only to cover the amount of steroid needed to cope with the infection but also to reduce the harmful effects that peaks and troughs of GC therapy cause to the immune system [30]. At this stage of disease, and for these steroid levels, circadian rhythm is no longer relevant. A very recent consensus on the management of critically ill adults with COVID-19 endorsed the same protocol in patients with refractory shock, as it is able to reduce the time to resolution and ICU length of stay [31]. It also recommended the use of hydrocortisone rather than other synthetic compounds (as often used in ICUs). Although a detailed mention of the characteristics of the several steroid formulations is beyond the scope of this paper, one should bear in mind the different anti-inflammatory action between the available compounds.

Hydration and electrolyte balance should also be monitored and corrected promptly, as in the second stage, peripheral shock can cause severe hypotension, requiring pharmacological intervention. In critical setting, additional mineralocorticoid therapy is not required for patients with primary AI, as hydrocortisone doses of more than $50 \mathrm{mg} /$ day have sufficient action at the mineralocorticoid receptor [32], although an increase to $100 \mu \mathrm{g} /$ day of fludrocortisone has been advocated in severe hypotension. As soon as the clinical condition allows, steroid infusion should be reduced accordingly, in order to avoid undesired detrimental effects. Finally, a very important recommendation comes from the increasing concern over the disseminated thromboembolic 
disease observed in severe COVID-19. Given the coagulation abnormalities associated with GC use [33], added to that of immune hyperactivation, endothelial disfunction and hepatic impairment observed in COVID-19, we strongly recommend introducing heparin early in AI patients [34], as soon as the symptoms evolve from mild to moderate or severe disease (4000 U every $12 \mathrm{~h}$ ).

SARS-CoV2 pandemic has reignited the debate on GC therapy in lung injury, and many scientific panels are working in these fateful hours to investigate their efficacy in treating COVID-19-related pneumonia. Outside all of this, and given the severity of COVID-19-associated syndrome, this opinion aims to underline that clinicians must not overlook the fact that AI patients depend on exogenous GC therapy for adequate stress response even to mild illness. In summary, available evidences on tailoring of GC stress regimens in COVID-19 are still weak and a more evidence-based approach is required to draw a definitive standardized protocol. The pathophysiology of immune response and systemic complications associated with infection set the pace, and treatment strategy should be adapted to the patient's clinical stage. For AI patients suspected to have COVID-19, who have mild upper respiratory track symptoms and no lung impairment, doubling the usual dose of hydrocortisone (alongside adequate fluid replacement) in a circadian fashion seems a safe measure to preserve the early activation of the immune response. The latter is also because symptoms are not specific and may last, even if minor, for 2 weeks or more. However, as soon as symptoms worsen, it is advisable to further increase the dose up to $100 \mathrm{mg}$, commence thromboembolic prophylaxis and consider prompt hospitalization as the condition could deteriorate within few hours. In hospital, parenteral treatment with high doses (200 mg) of continuous intravenous hydrocortisone is only required following evolution towards a critical stage (rapid drop in oxygenation) or adrenal crisis (Fig. 1).

Acknowledgements The authors thank Marie-Hélène Hayles for her medical writing assistance during the preparation of the manuscript.

Author contributions AMI-substantial contributions to conception of the manuscript, acquisition of data, analysis and interpretation of data, drafting the article, revising it critically for important intellectual content and final approval of the version to be submitted. GA-substantial contributions to drafting the article, revising it critically for important intellectual content and final approval of the version to be submitted; MB - substantial contributions to drafting the article, revising it critically for important intellectual content and final approval of the version to be submitted; AF-substantial contributions to drafting the article, revising it critically for important intellectual content and final approval of the version to be submitted; CG-substantial contributions to drafting the article, revising it critically for important intellectual content and final approval of the version to be submitted; RG-substantial contributions to drafting the article, revising it critically for important intellectual content and final approval of the version to be submitted; RP-substantial contributions to drafting the article, revising it critically for important intellectual content and final approval of the version to be submitted; RP-substantial contributions to conception of the manuscript, acquisition of data, analysis and interpretation of data, drafting the article, revising it critically for important intellectual content and final approval of the version to be submitted; VH-substantial contributions to conception of the manuscript, acquisition of data, analysis and interpretation of data, drafting the article, revising it critically for important intellectual content and final approval of the version to be submitted; MAV—substantial contributions to conception of the manuscript, acquisition of data, analysis and interpretation of data, drafting the article, revising it critically for important intellectual content and final approval of the version to be submitted; ES- - substantial contributions to conception of the manuscript, acquisition of data, analysis and interpretation of data, drafting the article, revising it critically for important intellectual content and final approval of the version to be submitted; CS—-substantial contributions to drafting the article, revising it critically for important intellectual content and final approval of the version to be submitted; CS-substantial contributions to drafting the article, revising it critically for important intellectual content and final approval of the version to be submitted; AL—substantial contributions to conception of the manuscript, substantial contributions to drafting the article, revising it critically for important intellectual content and final approval of the version to be submitted;

Funding No funding was used to produce this manuscript.

Data availability and material Not applicable.

\section{Compliance with ethical standards}

Conflict of interest AM.I. has received grants and advisory fees from Takeda and Novartis. G.A. has been Principal Investigator of Research Studies for Novartis; has received research grants from Novartis and Takeda; has received speaker fees from Novartis; and has received consulting fees from Novartis and Pfizer, Inc. as board member. M.B. has been Principal Investigator of Research Studies for Novartis; has been Investigator of Research Studies for Novartis, HRA Pharma and ViroPharma; and has received consulting fees from Novartis as board member. A.F. declares that he has received a speaker honorarium from Shire Italy S.p.A. C.G. has been Principal Investigator of Research Studies for Novo Nordisk and Lilly USA, LLC; has received research grants from Novo Nordisk and Lilly USA, LLC; has been an occasional consultant for Novartis, Pfizer, Inc., Ipsen and Shire; and has received speaker fees from Novo Nordisk, Lilly USA, LLC and Novartis. R.G. has been occasional consultant for Shire. R.P. has been Principal Investigator of Research Studies for Novartis, HRA Pharma, Ipsen, Shire, Corcept Therapeutics, Cortendo AB; Co-investigator of Research Studies for Pfizer; received research grants from Novartis, Pfizer, Ipsen, HRA Pharma, Shire, IBSA; has been an occasional consultant for Novartis, Ipsen, Pfizer, Shire, HRA Pharma, Cortendo AB, Ferring and Italfarmaco; and has received fees and honoraria for presentations from Novartis, Shire. C.S. has been occasional consultant for Shire and Ipsen. C.S. has been Principal Investigator of Research Studies for Novartis, Otsuka and Pfizer, Inc.; has been Co-investigator of Research Studies for Novartis and Lilly USA, LLC; has received research grants from Novartis, Lilly USA, LLC, Otsuka and Pfizer, Inc.; has been an occasional consultant for Novartis and Otsuka; and has received speaker fees for presentations from Otsuka and Lilly USA, LLC. A.L. has received grants and advisory fees from Takeda and Novartis. V.H., R.P., M.A.V and E.S. have no conflicts of interest.

Ethics approval It is an Opinion, with no original experimental or clinical data, and thus no requirement for ethical approval and formal consent is not required either. 
Consent to participate It is an Opinion, with no original experimental or clinical data, and thus consent to participate is not required.

Consent for publication Not applicable.

Code availability Not applicable.

\section{References}

1. Isidori AM, Arnaldi G, Boscaro M, Falorni A, Giordano C, Giordano R, Pivonello R, Pozza C, Sbardella E, Simeoli C, Scaroni C, Lenzi A, Italian Society of E (2019) Towards the tailoring of glucocorticoid replacement in adrenal insufficiency: the Italian Society of Endocrinology Expert Opinion. J Endocrinol Invest. https://doi.org/10.1007/s40618-019-01146-y

2. Baud D, Qi X, Nielsen-Saines K, Musso D, Pomar L, Favre G (2020) Real estimates of mortality following COVID-19 infection. Lancet Infect Dis. https://doi.org/10.1016/S1473-3099(20)30195 $-\mathrm{X}$

3. Onder G, Rezza G, Brusaferro S (2020) Case-fatality rate and characteristics of patients dying in relation to COVID-19 in Italy. JAMA. https://doi.org/10.1001/jama.2020.4683

4. Wu Z, McGoogan JM (2020) Characteristics of and important lessons from the coronavirus disease 2019 (COVID-19) outbreak in China: summary of a report of 72314 cases from the Chinese center for disease control and prevention. JAMA. https://doi. org/10.1001/jama.2020.2648

5. Newton AH, Cardani A, Braciale TJ (2016) The host immune response in respiratory virus infection: balancing virus clearance and immunopathology. Semin Immunopathol 38(4):471-482. https://doi.org/10.1007/s00281-016-0558-0

6. Shi Y, Wang Y, Shao C, Huang J, Gan J, Huang X, Bucci E, Piacentini M, Ippolito G, Melino G (2020) COVID-19 infection: the perspectives on immune responses. Cell Death Differ. https://doi. org/10.1038/s41418-020-0530-3

7. Sweeney RM, McAuley DF (2016) Acute respiratory distress syndrome. Lancet 388(10058):2416-2430. https://doi.org/10.1016/ S0140-6736(16)00578-X

8. Wang F, Nie J, Wang H, Zhao Q, Xiong Y, Deng L, Song S, Ma Z, Mo P, Zhang Y (2020) Characteristics of peripheral lymphocyte subset alteration in COVID-19 pneumonia. J Infect Dis. https:// doi.org/10.1093/infdis/jiaa150

9. Huang C, Wang Y, Li X, Ren L, Zhao J, Hu Y, Zhang L, Fan G, Xu J, Gu X, Cheng Z, Yu T, Xia J, Wei Y, Wu W, Xie X, Yin W, Li H, Liu M, Xiao Y, Gao H, Guo L, Xie J, Wang G, Jiang R, Gao Z, Jin Q, Wang J, Cao B (2020) Clinical features of patients infected with 2019 novel coronavirus in Wuhan, China. Lancet 395(10223):497-506. https://doi.org/10.1016/S0140 $-6736(20) 30183-5$

10. Guan WJ, Ni ZY, Hu Y, Liang WH, Ou CQ, He JX, Liu L, Shan H, Lei CL, Hui DSC, Du B, Li LJ, Zeng G, Yuen KY, Chen RC, Tang CL, Wang T, Chen PY, Xiang J, Li SY, Wang JL, Liang ZJ, Peng YX, Wei L, Liu Y, Hu YH, Peng P, Wang JM, Liu JY, Chen Z, Li G, Zheng ZJ, Qiu SQ, Luo J, Ye CJ, Zhu SY, Zhong NS, China Medical Treatment Expert Group for C (2020) Clinical characteristics of coronavirus disease 2019 in China. N Engl J Med. https://doi.org/10.1056/NEJMoa2002032

11. Figueroa-Parra G, Aguirre-Garcia GM, Gamboa-Alonso CM, Camacho-Ortiz A, Galarza-Delgado DA (2020) Are my patients with rheumatic diseases at higher risk of COVID-19? Ann Rheum Dis. https://doi.org/10.1136/annrheumdis-2020-217322

12. Halpin DMG, Faner R, Sibila O, Badia JR, Agusti A (2020) Do chronic respiratory diseases or their treatment affect the risk of SARS-CoV-2 infection? Lancet Respir Med. https://doi. org/10.1016/S2213-2600(20)30167-3

13. Wu C, Chen X, Cai Y, Xia J, Zhou X, Xu S, Huang H, Zhang L, Zhou X, Du C, Zhang Y, Song J, Wang S, Chao Y, Yang Z, Xu J, Zhou X, Chen D, Xiong W, Xu L, Zhou F, Jiang J, Bai C, Zheng J, Song Y (2020) Risk factors associated with acute respiratory distress syndrome and death in patients with coronavirus disease 2019 pneumonia in Wuhan, China. JAMA Intern Med. https://doi. org/10.1001/jamainternmed.2020.0994

14. Chrousos GP (1995) The hypothalamic-pituitary-adrenal axis and immune-mediated inflammation. N Engl J Med 332(20):13511362. https://doi.org/10.1056/NEJM199505183322008

15. Ruan SY, Lin HH, Huang CT, Kuo PH, Wu HD, Yu CJ (2014) Exploring the heterogeneity of effects of corticosteroids on acute respiratory distress syndrome: a systematic review and metaanalysis. Crit Care 18(2):R63. https://doi.org/10.1186/cc13819

16. Chaudhary NS, Donnelly JP, Moore JX, Baddley JW, Safford MM, Wang HE (2017) Association of baseline steroid use with longterm rates of infection and sepsis in the REGARDS cohort. Crit Care 21(1):185. https://doi.org/10.1186/s13054-017-1767-1

17. Venkatesh B, Finfer S, Myburgh J, Cohen J, Billot L (2018) Long-term outcomes of the ADRENAL trial. N Engl J Med 378(18):1744-1745. https://doi.org/10.1056/NEJMc1803563

18. Annane D, Renault A, Brun-Buisson C, Megarbane B, Quenot JP, Siami S, Cariou A, Forceville X, Schwebel C, Martin C, Timsit JF, Misset B, Ali Benali M, Colin G, Souweine B, Asehnoune K, Mercier E, Chimot L, Charpentier C, Francois B, Boulain T, Petitpas F, Constantin JM, Dhonneur G, Baudin F, Combes A, Bohe J, Loriferne JF, Amathieu R, Cook F, Slama M, Leroy O, Capellier G, Dargent A, Hissem T, Maxime V, Bellissant E (2018) Hydrocortisone plus fludrocortisone for adults with septic shock. N Engl J Med 378(9):809-818. https://doi.org/10.1056/NEJMo a1705716

19. Zhou YH, Qin YY, Lu YQ, Sun F, Yang S, Harypursat V, Tang SQ, Huang YQ, He XQ, Zeng YM, Li Y, Xu XL, Zhao T, Chen YK (2020) Effectiveness of glucocorticoid therapy in patients with severe novel coronavirus pneumonia: protocol of a randomized controlled trial. Chin Med J (Engl). https://doi. org/10.1097/CM9.0000000000000791

20. Teblick A, Peeters B, Langouche L, Van den Berghe G (2019) Adrenal function and dysfunction in critically ill patients. Nat Rev Endocrinol 15(7):417-427. https://doi.org/10.1038/s4157 4-019-0185-7

21. Russell CD, Millar JE, Baillie JK (2020) Clinical evidence does not support corticosteroid treatment for 2019-nCoV lung injury. Lancet 395(10223):473-475. https://doi.org/10.1016/S0140 $-6736(20) 30317-2$

22. Kaiser UB, Mirmira RG, Stewart PM (2020) Our response to COVID-19 as endocrinologists and diabetologists. J Clin Endocrinol Metab. https://doi.org/10.1210/clinem/dgaa148

23. Isidori AM, Venneri MA, Graziadio C, Simeoli C, Fiore D, Hasenmajer V, Sbardella E, Gianfrilli D, Pozza C, Pasqualetti P, Morrone S, Santoni A, Naro F, Colao A, Pivonello R, Lenzi A (2018) Effect of once-daily, modified-release hydrocortisone versus standard glucocorticoid therapy on metabolism and innate immunity in patients with adrenal insufficiency (DREAM): a single-blind, randomised controlled trial. Lancet Diabetes Endocrinol 6(3):173-185. https://doi.org/10.1016/S2213-8587(17)30398-4

24. Arafah BM (2020) Perioperative glucocorticoid therapy for patients with adrenal insufficiency: dosing based on pharmacokinetic data. J Clin Endocrinol Metab. https://doi.org/10.1210/cline $\mathrm{m} / \mathrm{dgaa} 042$

25. Castanon-Cervantes O, Wu M, Ehlen JC, Paul K, Gamble KL, Johnson RL, Besing RC, Menaker M, Gewirtz AT, Davidson AJ (2010) Dysregulation of inflammatory responses by chronic 
circadian disruption. J Immunol 185(10):5796-5805. https://doi. org/10.4049/jimmunol.1001026

26. Polidarova L, Houdek P, Sladek M, Novosadova Z, Pacha J, Sumova A (2017) Mechanisms of hormonal regulation of the peripheral circadian clock in the colon. Chronobiol Int 34(1):116. https://doi.org/10.1080/07420528.2016.1231198

27. Coiffard B, Diallo AB, Culver A, Mezouar S, Hammad E, Vigne C, Nicolino-Brunet C, Dignat-George F, Baumstarck K, Boucekine M, Leone M, Mege JL (2019) Circadian rhythm disruption and sepsis in severe trauma patients. Shock 52(1):29-36. https://doi.org/10.1097/SHK.0000000000001241

28. Gibbison B, Keenan DM, Roelfsema F, Evans J, Phillips K, Rogers CA, Angelini GD, Lightman SL (2020) Dynamic pituitaryadrenal interactions in the critically ill after cardiac surgery. J Clin Endocrinol Metab. https://doi.org/10.1210/clinem/dgz206

29. Pivonello R, Simeoli C, De Martino MC, Cozzolino A, De Leo M, Iacuaniello D, Pivonello C, Negri M, Pellecchia MT, Iasevoli F, Colao A (2015) Neuropsychiatric disorders in Cushing's syndrome. Front Neurosci 9:129. https://doi.org/10.3389/fnins .2015 .00129

30. Prete A, Taylor AE, Bancos I, Smith DJ, Foster MA, Kohler S, Fazal-Sanderson V, Komninos J, O'Neil DM, Vassiliadi DA, Mowatt CJ, Mihai R, Fallowfield JL, Annane D, Lord JM, Keevil BG, Wass JAH, Karavitaki N, Arlt W (2020) Prevention of adrenal crisis: cortisol responses to major stress compared to stress dose hydrocortisone delivery. J Clin Endocrinol Metab. https:// doi.org/10.1210/clinem/dgaa133

31. Alhazzani W, Moller MH, Arabi YM, Loeb M, Gong MN, Fan E, Oczkowski S, Levy MM, Derde L, Dzierba A, Du B, Aboodi
M, Wunsch H, Cecconi M, Koh Y, Chertow DS, Maitland K, Alshamsi F, Belley-Cote E, Greco M, Laundy M, Morgan JS, Kesecioglu J, McGeer A, Mermel L, Mammen MJ, Alexander PE, Arrington A, Centofanti JE, Citerio G, Baw B, Memish ZA, Hammond N, Hayden FG, Evans L, Rhodes A (2020) Surviving sepsis campaign: guidelines on the management of critically ill adults with coronavirus disease 2019 (COVID-19). Intensive Care Med. https://doi.org/10.1007/s00134-020-06022-5

32. Arlt W, Society for Endocrinology Clinical C (2016) SOCIETY FOR ENDOCRINOLOGY ENDOCRINE EMERGENCY GUIDANCE: Emergency management of acute adrenal insufficiency (adrenal crisis) in adult patients. Endocr Connect 5(5):G1-G3. https://doi.org/10.1530/EC-16-0054

33. Pivonello R, Isidori AM, De Martino MC, Newell-Price J, Biller BM, Colao A (2016) Complications of Cushing's syndrome: state of the art. Lancet Diabetes Endocrinol 4(7):611-629. https://doi. org/10.1016/S2213-8587(16)00086-3

34. Isidori AM, Minnetti M, Sbardella E, Graziadio C, Grossman AB (2015) Mechanisms in endocrinology: the spectrum of haemostatic abnormalities in glucocorticoid excess and defect. Eur J Endocrinol 173(3):R101-113. https://doi.org/10.1530/ EJE-15-0308

Publisher's Note Springer Nature remains neutral with regard to jurisdictional claims in published maps and institutional affiliations. 